\title{
TURISMO E EMPREGO NA ECONOMIA BRASILEIRA
}

\author{
Ivo Torres*
}

\begin{abstract}
RESUMO: Num período de recessầo, como o atual momento da economia brasileira, a questão do emprego passa a merecer tratamento especial. Nesse sentido, setores relativamente mais intensivos em mão-de-obra, como o caso do Turismo, tendem a ser priorizados pelas políticas governamentais. Este artigo propõe-se a indicar a importância do Turismo como gerador de emprego, com base em estimativas preliminares dos multiplicadores de renda e de emprego, e da matriz das relaçōes intersetoriais do Brasil. Admitidas algumas hipóteses restritivas e reconhecendo-se as precariedades dos dados disponíveis, pode-se chegar a algumas evidências de que o Turismo deve compor, juntamente com outras atividades absorvedoras de mão-de-obra, o elenco de setores estratégicos, nas políticas de estabilização do nível de emprego e suas políticas de crescimento, onde a maximização do fator mão-deobra prevaleça sobre a da produção.
\end{abstract}

UNITERMOS: Turismo: economia; emprego. Economia: turismo e emprego. Emprego: turismo.

ABSTRACT: In recession periods as the present Brazilian economic situation, the problem of unemployment deserves special consideration. In this sense areas relatively more labor-intensive, as Tourism, come to be considered prioritaries by government policies. This article intends to point out the importance of tourism in the opening of new jobs, making full use of preiiminary data regarding income and employment, and the matrix of related areas in Brazil. Given some restrictive hypotheses and accepting as a fact the shortcomings of available data, one would come to some evidences that tourism, allied to other labor-intensive activities, might compose a roll of strategic sectors when dealing with eimployment level stabilization and its growing policies where labor maximization prevails over production.

KEY WORDS: Tourism: economy; employment. Economy: tourism and employment. Employment: tourism.

(*) Professor Associado do Depto. de Economia da Faculdade de Economia e Administração da Universidade de São Paulo.

End. para corresp.: FEA/USP - Cidade Universitária - Av. Prof. Luciano Gualherto. 908 - CEP 05508 - São Paulo - SP - Brasil. 


\section{INTRODUÇÃO}

Diante das medidas anti-inflacionárias do governo, que têm provocado uma recessão na economia brasileira, alguns setores podem e devem ser considerados como amortecedores com relação à desutilização do fator trabalho. A existência de diferenças nas relações trabalho/produção dos diferentes setores que compõem o produto nacional faz com que as políticas adotadas afetem os níveis de emprego de formas diferenciadas. Assim, o mesmo nível de produto pode ser realizado com níveis diferentes de emprego, mostrando a possibilidade de políticas estabilizadoras serem utilizadas de forma a promover menor (ou maior) queda (ou elevação) do emprego.

Este artigo pretende mostrar que o Setor Turismo pode desempenhar o papel de amoriecedor do nível de emprego, se as metas de desenvolvimento e/ou preservação dos seus efeitos recessivos forem perseguidas.

\section{MULTIPLICADORES DE EMPREGO}

A idéia básica que dá suporte ao desenvoivimento deste item é a existência de um coeficiente ligando o aumento (ou redução) de gastos com o aumento (ou redução) de emprego, para, em seguida, mostrar que o Turismo pode converter-se, diante de uma recessão, em um elemento estratégico para o nível de emprego.

A aplicação do multiplicador, destacando-se os gastos autônomos, é imediata.

Seja: $\mathrm{Y}$, a renda regional

\section{C, o consumo}

M, a importação

$\mathrm{X}$, gastos autônomos

Assim, a renda pode ser expressa por:

$$
\mathrm{Y}=\mathrm{C}+\mathrm{X}-\mathrm{MR}
$$

Sabe-se que:

$$
\begin{aligned}
& \mathrm{CR}=\mathrm{a}+\mathrm{b}(\mathrm{Y}-\mathrm{R}) \\
& \mathrm{M}=\mathrm{mY} \\
& \mathrm{R}=\mathrm{rY}
\end{aligned}
$$

onde R é a tributação.

Obtém-se:

$$
Y=a+b Y-m Y-b r Y+X
$$

onde

$$
Y=\frac{1}{1-b+m+b r}(a+X)
$$

Nesse sentido, um acréscimo em gastos $\Delta \mathrm{X}$ geraria um acréscimo $\triangle Y$ na renda, da seguinte forma:

$$
\Delta Y=\frac{1}{1-b+m+b r} \quad X
$$

onde a expressão $\frac{1}{1-b+m+b r}$ seria o multiplicador igual a $\mathrm{K}$.

Assim, genericamente, o multiplicador é definido como o efeito marginal de uma variável sobre outra, da qual a primeira é um componente; no presente caso, o efeito marginal dos gastos autônomos sobre a renda.

A transformação dos efeitos sobre a renda em efeitos sobre o emprego também é imediata.

Sendo

$$
\Delta \mathrm{Y}=\mathrm{K} \Delta \mathrm{X}
$$

o acréscimo de renda, $\Delta \mathrm{Y}$ pode ser expresso também por:

$$
\Delta Y=P M N \Delta N
$$

onde PMN é a produtividade média do trabalho e $\triangle \mathrm{N}$ é o acréscimo de trabalho (emprego). Substituindo (2) em (1) tem-se: 
ou

$$
\Delta \mathrm{N}=\mathrm{K} \frac{1}{\mathrm{PMN}} \Delta \mathrm{X}
$$

Denominando $\frac{\mathrm{K}}{\mathrm{PMN}}=\mathrm{KN}$

$$
\text { tem-se } \Delta N=K N \Delta X
$$

Formula esta que se refere ao aumento do emprego gerado por um dado aumento de gastos.

Desse modo, basta, então, estimarem-se os valores de K e PMN para se estabelecer o impacto dos gastos autônomos sobre o nível de emprego.

\section{ESTIMAÇÃO DOS PARÂMETROS ESTRATÉGICOS}

Como a finalidade deste item é mostrar as possíveis repercussões do aumento de gastos na determinação da renda, deve-se estabelecer uma forma de estimar os parâmetros estratégicos, isto é, os coeficientes que são relevantes para a determinação dos multiplicadores. Assim, a propensão marginal a consumir, a importar e a arrecadar são basicamente os principais determinantes do multiplicador e, dessa forma, deve-se concentrar na estimação das mesmas.

A partir do trabalho de Santos Jr. ${ }^{1}$, os valores dos parâmetros foram os seguintes:

$$
\begin{aligned}
& \mathrm{b}=0,79 \text { propensão a consumir } \\
& \mathrm{r}=0,16 \text { propensão a arrecadar } \\
& \mathrm{m}=0,13 \text { propensão a importar }
\end{aligned}
$$

A magnitude do multiplicador foi estabelecida em: $\mathrm{k}=2,13 \mathrm{mul}-$ tiplicador da renda.

Quanto à produtividade, com informaçōes do IBGE para os anos de 1988 a 1990, estimou-se a seguinte magnitude em US\$*:

(*) O valor PIB foi em média 351,914 bilhōes de dólares, enquanto a população ocupada esteve ao redor de 59 milhōes.
Calculando-se o multiplicador de emprego tem-se que:

$$
\Delta N=0,00035 \Delta X
$$

Assim um decréscimo de US\$10.000,00 nos gastos autônomos geraria uma redução de 3,5 empregos.

\section{SETOR TURISMO E NÍVEL DE EMPREGO}

Teoricamente a produtividade utilizada para a economia brasileira nada mais representa que uma média ponderada das produtividades dos setores que compōem o Produto Interno, onde as ponderaçōes são as participações de tais setores no total. Além disso, tais produtividades representam o inverso dos coeficientes de absorção de mãode-obra. Dessa forma, a alteração da relação média trabalho/produção (coeficiente de absorção) pode diminuir o impacto negativo sobre o nível de emprego.

Embora ainda não se tenha uma estimação confiável sobre o coeficiente de absorção de mão-de-obra no setor turismo, sabe-se que grande parte das atividades que o compōem se encontram no setor terciário (85\% das atividades), o qual apresenta, pelos dados da matriz das relações intersetoriais do Brasil, um coeficiente de absorção que supera em quase $50 \%$ a média nacional.

Portanto, políticas estabilizadoras que preservem ou afetam pouco o setor, tenderão a alterar a relação média Trabalho/Produção, reduzindo o grau de desemprego por unidade de queda de gastos gerais, servindo, assim, como um amortecedor do nível de desemprego.

Admitindo-se que a participação das atividades que compõem o setor passe a representar de 10 a $15 \%$ do PIB, considerando o coeficiente de absorção $50 \%$ acima da média da economia e admitindo-se que a queda na produção seja de tal forma a preservar o Setor Turismo, pode-se calcular que haverá uma redução do nível esperado de desemprego em aproximadamente $8 \%$, isto é, de cada 100 (cem) desempregados que seriam gerados, somente $92 \%$ se confirmariam. 


\section{OBSERVAÇÕES FINAIS}

Embora esse artigo seja ainda bastante preliminar, quer pelo desenvolvimento metodológico rudimentar adotado, quer pela carência de informaçoes mais precisas, quer pelas hipóteses restritivas adotadas, fica claro que o Setor Turismo deve ser encarado, juntamente com outros setores absorvedores de mão-de-obra como setores estratégicos; isto tanto com relação às políticas de estabilização do nível de emprego, quanto às políticas de crescimento, onde a maximização a ser perseguida é a utilização da mão-de-obra em primeiro lugar, e, a seguir, a produção.

\section{REFERÊNCIA BIBLIOGRÁFICA}

1. SANTOS JR. L. M. dos. Os efeitos do politica fiscal sobre o nivel de produção no Brasil. São Paulo, FEA/JSP, 1991. (Dissertação de Mestrado) 